\title{
Reduction in clinical response to empiric antimicrobial therapy of febrile \\ granulocytopenic patients receiving TMP/SMX infection prophylaxis
}

ERIC J BOW, MD, Joseph L PATER, MD, ThOMAS J LOUIE, MD, RONALD FELD, MD, LIONEL MANDELL, MD, Hugh G Robson, MD, Anthony Chow, MD, Andrew Belch, MD, Lilly Miedzinski, MD, NANCy PAUl, MA,

Catherine R ElLIOT, MSC, ANDREW R Willan, PhD

\begin{abstract}
EJ Bow, JL PATER, TJ Lovie, et al. Reduction in clinical response to empiric antimicrobial therapy of febrile granulocytopenic patients receiving TMP/SMX for infection prophylaxis. Can J Infect Dis 1992; 3(5):235-239. In the course of a multicentre clinical trial evaluating two antibacterial regimens for the empiric treatment of suspected infection in febrile neutropenic cancer patients, a suboptimal response was noted among recipients of antibacterial prophylaxis with trimethoprim/sulphamethoxazole (TMP/SMX). Multivariate analysis identified TMP/SMX prophylaxis as a predictor of poor outcome independent of other variables such as classification of infection, marrow recovery, neutrophil count at first fever, indwelling central venous catheter use, and underlying disease. This effect appeared to be restricted to recipients of tobramycin plus ticarcillin (TT). TMP/SMX suppresses potentially pathogenic aerobic Gram-negative bacilli and allows colonization and subsequent infection by Gram-positive microorganisms against which TT-like regimens have limited activity. Recognition of this phenomenon may permit a more appropriate selection of antibacterial agents for the therapy of suspected infection in the neutropenic patient.
\end{abstract}

Key Words: Antibacterial chemoprophylaxis, Neutropenia, Trimethoprim/sulphamethoxazole

\section{Réduction de la réponse clinique au traitement antimicrobien empirique chez des patients granulopéniques et fébriles sous protocole prophylactique associant triméthoprime et sulphaméthoxazole}

RÉSUMÉ: Au cours d'un essai clinique multicentrique visant à évaluer deux protocoles antibactériens dans le traitement empirique d'une infection possible chez des patients cancéreux, neutropéniques et fébriles, on a noté une réponse suboptimale chez les receveurs d'une prophylaxie antibactérienne associant la triméthoprime et le sulphaméthoxazole (TMP/SMX). Une analyse multifactorielle a permis d’identifier la

National Cancer Institute of Canada, Clinical Trials Group. Queen's University. Kingston. Ontario

Correspondence: Dr EJ Bow, Infectious Diseases/Haematology-Oncology Chief. GD6 Oncology Service, Health Sciences Centre. 820 Sherbrook Street. Winnipeg. Manitoba R3A 1 R9

Reprints: Dr Joseph L Pater, National Cancer Institute of Canada, Clinical Trials Group, Queen's University. 82-84 Barrie Street.

Kingston, Ontario K7L 3N6

Received for publication April 19, 1990. Accepted August 27, 1991 
TMP/SMX comme prédicteur de mauvais résultats indépendamment des autres variables telles que le type d'infection, le prélèvement de moelle, le taux des polynucléaires neutrophiles à la première fièvre. l'utilisation d'un cathéter d'hyperalimentation à demeure et une maladie sous-jacente. Cet effet semblait limité aux patients traités sous tobramycine plus ticarcilline (TT); toutefois, la TMP/SMX supprime les bacilles gram négatif potentiellement pathogènes et permet la colonisation et l'infection subséquente par des micro-organismes gram positif contre lesquels les protocoles de traitement de type TT ont une activité limitée. La reconnaissance de ce phénomène permet de mieux choisir les agents antibactériens destinés au traitement des infections possibles chez le patient neutropénique.

T RIMETHOPRIM/SULPHAMETHOXAZOLE (TMP/SMX) HAS been used in many centres for infection prophylaxis in granulocytopenic cancer patients. Prophylactic success has been reported by some investigators but not by others (1). TMP/SMX may permit colonization by resistant organisms such as fungi (2), aerobic Gramnegative bacilli (3) and Gram-positive cocci such as Staphylococcus epidermidis $(4,5)$.

During the course of a multicentre trial comparing the efficacy and toxicity of two empiric systemic antibiotic regimens for suspected infection in febrile granulocytopenic patients, it was noted that patients who received antimicrobial prophylaxis with TMP/SMX had a poorer outcome compared with those who did not (6). This observation has not been previously reported. Multivariate analytical techniques were used to separate the effect of TMP/SMX prophylaxis from other prognostic variables as predictors of outcome.

\section{PATIENTS AND METHODS}

This was a randomized multicentre trial conducted under the direction of the Clinical Trials Group of the National Cancer Institute of Canada. The protocol and clinical results are reported elsewhere (6). Briefly, 195 granulocytopenic patients (less than $1.0 \times 10^{9}$ granulocytes/L) with their first episode of fever (defined as an oral temperature greater than $38^{\circ} \mathrm{C}$ noted on three occasions over a $12 \mathrm{~h}$ period) were randomized to receive intravenous ticarcillin ( 3 g every $4 \mathrm{~h}$ ) plus either intravenous moxalactam ( 2 g every $6 \mathrm{~h}$ ) or intravenous tobramycin $(1.25 \mathrm{mg} / \mathrm{kg}$ every $6 \mathrm{~h})$. There was no significant difference between the study groups (Table 1). TMP/SMX was administered for infection prophylaxis in a nonrandomized manner according to local institutional policy, in doses of $160 \mathrm{mg}$ TMP and $800 \mathrm{mg}$ SMX orally every $12 \mathrm{~h}$. Prophylaxis was discontinued when the patient became febrile and entered the trial. Patients were classified according to whether they had received more than five days of prophylaxis (the minimum period required to suppress aerobic Gramnegative fecal microflora) $(2,7)$.

Analysis: The outcomes of the infectious episodes were categorized as 'complete response', 'temporary improvement' and 'failure'. 'Complete response' was defined as complete disappearance of all symptoms and signs of infection persisting for four days after cessation of antibiotics; 'temporary improvement' as a fall in temperature of $1.7^{\circ} \mathrm{C}$ or to normal accompanied by improve- ment in any clinical signs; and 'failure' as the absence of improvement or improvement only after addition of alternative antibiotics. For the purpose of this analysis two outcomes were used: response, which included complete response and those temporary improvements which were felt to represent a beneficial effect of protocol treatment; failure, which included all other cases.

The statistical significance of relationships between individual prognostic factors and response was assessed using the contingency $\chi^{2}$ test. The simultaneous effect on outcome of multiple prognostic factors was evaluated with a multiple logistic model. This model identifies the contribution of single prognostic variables to outcome taking into account other factors in the model. Finally, a log-linear model was used to assess whether the effect of TMP/SMX on outcome varied with treatment assignment, that is, whether an interaction was present. All analyses were performed using programs available in BMDP (8). Associations were considered significant at $\mathrm{P}<0.05$.

\section{TABLE 1}

Patient characteristics in a randomized multicentre trial comparing the efficacy and toxicity of two empiric systemic antibiotic regimens for suspected infection in febrile granulocytopenic patients

\begin{tabular}{|c|c|c|}
\hline & \multicolumn{2}{|c|}{ Allocation } \\
\hline & $\begin{array}{l}\text { Moxalactam } \\
\text { /ticarcillin }\end{array}$ & $\begin{array}{l}\text { Tobramycin } \\
\text { /ticarcillin }\end{array}$ \\
\hline Evaluable first febrile episodes & 106 & 89 \\
\hline Mean age (years) & 50 & 53 \\
\hline Age range (years) & 18 to 82 & 18 to 82 \\
\hline Male/female ratio & 0.83 & 1.14 \\
\hline \multicolumn{3}{|l|}{ Underlying diseases } \\
\hline Acute myeloid leukemia & 44 & 42 \\
\hline Acute lymphoblastic leukemia & 9 & 2 \\
\hline $\begin{array}{l}\text { Chronic myeloid leukemia, } \\
\text { blastic crisis }\end{array}$ & 8 & 1 \\
\hline Chronic lymphoid leukemia & 4 & 5 \\
\hline Lymphoma & 14 & 16 \\
\hline Solid tissue malignancy & 21 & 15 \\
\hline Marrow aplasia & 1 & 4 \\
\hline Other & 5 & 4 \\
\hline Total & 106 & 89 \\
\hline \multicolumn{3}{|l|}{$\begin{array}{l}\text { Durations of prophylactic } \\
\text { TMP/SMX }\end{array}$} \\
\hline More than five days & 42 & 35 \\
\hline Five days or less & 64 & 54 \\
\hline
\end{tabular}




\section{RESULTS}

A total of 244 febrile granulocytopenic patients experiencing their first episodes of fever were entered into the study. Of these, 195 were evaluable for response; 106 received moxalactam plus ticarcillin (MT); and 89 received tobramycin plus ticarcillin (TT). The reasons for the inevaluability of the remaining 49 patients are detailed elsewhere (6). Forty-two MT recipients (40\%) and 35 TT recipients (39\%) received more than five days of TMP/SMX prophylaxis. Patients receiving TMP/SMX were more likely to have acute leukemia as the underlying illness, more likely to have had a Hickman central venous catheter, and more likely to have profound granulocytopenia than patients who had received no prophylaxis. These relationships were not unexpected, as prophylactic TMP/SMX and Hickman catheters are more likely to be used in patients with acute leukemia, a group with more profound and longer duration granulocytopenia.

On multivariate analysis, differences in underlying disease did not appear to account for adverse outcomes associated with TMP/SMX prophylaxis (Table 2). The classification of infection, pattern of granulocyte recovery, presence of an indwelling central venous catheter, and use of TMP/SMX for more than five days correlated independently with response.

To examine the effect of TMP/SMX on response rates, the use of TMP/SMX was evaluated by disease classification and allocation (Table 3). TMP/SMX use had no influence on response rates in MT recipients. A negative influence on outcome was observed only in TT recipients. The effect was most evident in TMP/SMX recipients who had acute leukemia, as there was a lower proportion of nonleukemics in the group receiving more than five days of TMP/SMX.

Because TMP/SMX prophylaxis may influence the etiology of infection, outcome was evaluated with respect to TMP/SMX use, allocation and infecting pathogen. Based on all the participating centres, a trend towards more Gram-positive infections was demonstrated among patients receiving more than five days of TMP/SMX (12 of 19,63\%) compared with those who did not (18 of $37,49 \%$ ). However, data from one of the centres where TMP/SMX is used extensively (Winnipeg,
Manitoba) show that TMP/SMX recipients had significantly more Gram-positive infections than those who did not receive TMP/SMX prophylaxis (nine of 10 and five of 15, respectively, $\chi^{2}$ 5.689, $\left.\mathrm{P}=0.02\right)$. Of patients with microbiologically documented infection there were eight failures among TMP/SMX recipients allocated to receive TT. Two of these were associated with strains of Escherichia coli resistant to both anti-

\section{TABLE 2}

Oułcome according to categories of prognostic factors by multiple logistic regression analysis in a randomized multicentre trial comparing the efficacy and toxicity of two empiric systemic antibiotic regimens for suspected infection in febrile granulocytopenic patients

\begin{tabular}{|c|c|c|c|c|c|}
\hline \multirow[b]{2}{*}{ Factors } & \multicolumn{3}{|c|}{ Response } & \multicolumn{2}{|c|}{ P value } \\
\hline & No & Yes & $\%$ Yes & 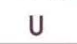 & M \\
\hline Sex & & & & 0.41 & 0.40 \\
\hline Male & 38 & 55 & 59 & & \\
\hline Female & 37 & 65 & 64 & & \\
\hline Allocation & & & & 0.26 & 0.68 \\
\hline Moxalactam/ticarcillin & 37 & 69 & 65 & & \\
\hline Tobramycin/ticarcillin & 38 & 51 & 57 & & \\
\hline Classification of infection & & & & 0.11 & 0.03 \\
\hline \multicolumn{6}{|l|}{ Microbiologically documented } \\
\hline Bacteremic & 19 & 17 & 47 & & \\
\hline Nonbacteremic & 10 & 10 & 50 & & \\
\hline Clinically documented & 20 & 41 & 67 & & \\
\hline Possible infection & 26 & 52 & 57 & & \\
\hline Underlying disease & & & & 0.08 & 0.34 \\
\hline Leukemia & 50 & 65 & 56 & & \\
\hline Other & 25 & 55 & 68 & & \\
\hline \multicolumn{4}{|c|}{ Granulocyte recovery pattern ( $\left.\times 10^{9} / \mathrm{L}\right)$} & 0.02 & 0.02 \\
\hline$<0.1$ to $<0.1$ & 25 & 20 & 44 & & \\
\hline$<0.1$ to $>0.1$ & 20 & 54 & 73 & & \\
\hline$>0.1$ to $<0.1$ & 17 & 24 & 58 & & \\
\hline$>0.1$ to $>0.1$ & 13 & 22 & 63 & & \\
\hline Prophylactic TMP/SMX & & & & 0.03 & 0.05 \\
\hline More than five days & 37 & 40 & 52 & & \\
\hline Less than or equal to five days & 38 & 80 & 69 & & \\
\hline \multicolumn{4}{|c|}{ Indwelling central venous catheter } & 0.02 & 0.02 \\
\hline No & 34 & 75 & 68 & & \\
\hline Yes & 26 & 25 & 49 & & \\
\hline No data & 15 & 20 & & & \\
\hline
\end{tabular}

M Multivariate: TMP/SMX Trimethoprim/sulphamethoxazole: U Univariate

\section{TABLE 3}

Response rates according to allocation, the use of prophylaxis, and underlying illness in a randomized multicentre trial comparing the efficacy and toxicity of two empiric systemic antibiotic regimens for suspected infection in febrile granulocytopenic patients

\begin{tabular}{|c|c|c|c|c|}
\hline & \multicolumn{2}{|c|}{ Moxalactam/ticarcillin } & \multicolumn{2}{|c|}{ Tobramycin/ticarcillin } \\
\hline & $\mathrm{TMP} / \mathrm{SMX} \leq \mathbf{5}$ days & $\mathrm{TMP} / \mathrm{SMX}>5$ days & $\mathrm{TMP} / \mathrm{SMX} \leq 5$ days & $\mathrm{TMP} / \mathrm{SMX}>5$ days \\
\hline \multicolumn{5}{|c|}{ Underlying illness } \\
\hline Leukemia & 19 of 34 & 19 of 31 & 18 of $24^{\dagger}(75 \%)$ & 9 of $26^{\dagger}(35 \%)$ \\
\hline Other & 23 of 30 & 8 of 11 & 20 of $30 \quad(67 \%)$ & 4 of $9 \quad(44 \%)$ \\
\hline Total & 42 of 64 & 27 of 42 & 38 of $54^{\ddagger}(70 \%)$ & 13 of $35^{\ddagger}(37 \%)$ \\
\hline
\end{tabular}

TMP/SMX Trimethoprim/sulphamethoxazole: ${ }^{\dagger} P<0.01 ;{ }^{\ddagger} P<0.01$ 
biotics, and two were associated with Gram-negative bacilli susceptible to both antibiotics. The four remaining failures had Gram-positive infections associated with resistance to both antibiotics in one case (Streptococcus bovis), resistance to tobramycin in two cases (a viridans group streptococcus and Staph epidermidis), and susceptibility to both antibiotics in one case (Bacillus species). Because of the retrospective nature of this study, the majority of these organisms were not saved for further investigations into the relationship between TMP/SMX resistance and resistance to TT.

\section{DISCUSSION}

Multivariate analytical techniques have proved useful for identifying important variables for predicting outcome of empiric therapy in febrile granulocytopenic cancer patients. Other investigators have shown the initial granulocyte count, granulocyte recovery pattern, site of infection and bacteriologic confirmation of infection to be important prognostic variables $(9,10)$. In the present multicentre study similar techniques were used to identify TMP/SMX prophylaxis as a predictor of poor outcome independent of other factors known to influence the outcome of empiric antibiotic therapy in this patient population. Although the effect of TMP/SMX prophylaxis on outcome was independent of underlying disease, use of indwelling central venous catheters, granulocyte recovery pattern, infection classification, and differences between the participating institutions, it was dependent upon regimen allocation. The poorer response rate was observed only in TT recipients who had received TMP/SMX prophylaxis.

The relationship between TMP/SMX prophylaxis and poor outcome in TT recipients was examined. First, TMP/SMX can allow colonization and subsequent infection by microorganisms that may be cross-resistant to TMP/SMX and to the TT regimen $(3,11)$. The present study, however, identified only two $E$ coli bacteremias and one Strep bovis bacteremia resistant to TT among the TT failures. The remaining five failures were due to microorganisms susceptible to one or both of the agents in the regimen, suggesting that other factors in addition to drug susceptibility were important in determining outcome.

Second, TMP/SMX suppresses aerobic Gram-negative bacilli in the gastrointestinal tract, and allows colonization by Gram-positive cocci such as Staph epidermidis and viridans streptococci $(2,4,12)$. This fact, together with the increased integumental damage due to cytotoxic chemotherapeutic agents used for cancer treatment, may account for the observed increase in proportion of Gram-positive infections among TMP/ SMX recipients $(4,5,12,13)$. In contrast, other reports link the use of indwelling central venous lines to an increased incidence of Gram-positive infections in immunocompromised patients $(1,14)$. The present study suggests that indwelling central venous catheters and
TMP/SMX are independent factors increasing the risk of Gram-positive infection.

Antipseudomonal penicillin plus aminoglycoside or broad-spectrum cephalosporin plus aminoglycoside combinations appear to have limited activity against Gram-positive infections in neutropenic patients (1517). Tobramycin is not particularly active in vitro against streptococci (18), and the combination of ticarcillin with an aminoglycoside has not been successful in a series of single Gram-positive bacteremias, most of which were due to Staph epidermidis (15). Superinfection with TT-resistant Staph epidermidis has been reported in neutropenic patients receiving TMP/SMX and TT (19). In fact, the occurrence of Gram-positive breakthrough bacteremia appears to be relatively common among recipients of antipseudomonal penicillin plus aminoglycoside regimens (20-22). The addition to the regimen of a specific Gram-positive agent such as vancomycin appears to reduce significantly the morbidity associated with the febrile episode $(20,21,23,24)$.

The interaction between TMP/SMX, TT and outcome in the present study is coupled to the predominance of Gram-positive infection observed in the trial and the suboptimal responses in TT recipients (6). The authors feel that TMP/SMX in the present study, as in others $(2,12,13)$, selected for Gram-positive pathogens against which TT alone may have limited activity. Reports from other centres suggest that the suboptimal activity observed for TT against Gram-positive pathogens is a phenomenon applicable to other antipseudomonal penicillin or broad-spectrum cephalosporin plus aminoglycoside combinations (15-17,20,22). Accordingly, the authors suggest that febrile neutropenic patients who receive empiric therapy with extended spectrum betalactams plus aminoglycoside regimens following TMP/ SMX prophylaxis will likely require regimen modification with a Gram-positive agent such as vancomycin.

ACKNOWLEDGEMENTS: This study was supported in part by the National Cancer Institute of Canada and Eli Lilly Co (Canada) Ltd.

\section{REFERENCES}

1. Pizzo PA. Granulocytopenia and cancer therapy - Past problems, current solutions, future challenges. Cancer 1984:54:2649-61.

2. Bow EJ, Louie TJ, Riben PD, McNaughton RD, Harding GKM, Ronald AR. Randomized controlled trial comparing trimethoprim-sulfamethoxazole and trimethoprim for infection prophylaxis in hospitalized granulocytopenic patients. Am J Med 1984;76:223-33.

3. Wilson JM, Guiney DG. Failure of oral trimethoprim-sulfamethoxazole prophylaxis in acute leukemia: Isolation of resistant plasmids from strains of enterobacteriaceae causing bacteremia. N Engl J Med 1982:306: 16-20.

4. Bow EJ, Rayner E, Scott BA, Louie TJ. Selective gut decontamination with nalidixic acid or 
trimethoprim-sulfamethoxazole for infection prophylaxis in neutropenic cancer patients: Relationship of efficacy to antimicrobial spectrum and timing of administration. Antimicrob Agents Chemother 1987;31:551-7.

5. Wade JC, Schimpff SC, Newman KA, Wiernik PH. Staphylococcus epidermidis: An increasing cause of infection in patients with granulocytopenia. Ann Intern Med 1982;97:503-8.

6. Feld R, Louie TJ, Mandell L, et al. A multicentre comparative trial of tobramycin and ticarcillin versus moxalactam and ticarcillin in febrile neutropenic patients. Arch Intern Med 1985;145:1083-8.

7. Gurwith MJ, Brunton JL, Lank BA, Harding GKM, Ronald AR. A prospective controlled investigation of prophylactic trimethoprim/sulfamethoxazole in hospitalized granulocytopenic patients. Am J Med 1978; 143:248-56

8. Dixon WJ, Broro BD, eds. BMPD-79. Berkeley: University of California Press, 1979.

9. EORTC International Antimicrobial Therapy Project Group. Empirical therapy in febrile granulocytopenic patients. Top Paediatr 1979;1:113-24.

10. Pennington JE. Fever, neutropenia and malignancy: A clinical syndrome in evolution. Cancer 1977:39:1345-9.

11. Riou B, Richard C, Rimailho A, Auzepy P. Potential risks of trimethoprim-sulfamethoxazole prophylaxis in neutropenic patients. J Infect Dis 1984;151:969.

12. Bow EJ, Rayner E, Louie TJ. Comparison of norfloxacin with cotrimoxazole for infection prophylaxis in acute leukemia. Am J Med 1988;84:847-54.

13. Weisman SJ, Scoopo FJ, Johnson GM, Altman AJ, Quinn JJ. Septicemia in pediatric oncology patients: The significance of viridans streptococcal infections. J Clin Oncol 1990;8:453-9.

14. Winston DJ, Dudnick DV, Chapin M, Wo WG, Gale RP, Martin MJ. Coagulase-negative staphylococcal bacteremia in patients receiving immunosuppressive therapy. Arch Intern Med 1983;143:32-6.

15. Klastersky J, Glauser MP, Schimpff SC, Zinner SH, Gaye $\mathrm{H}$, the EORTC Antimicrobial Therapy Project Group. Prospective randomized comparison of three antibiotic regimens for empiric therapy of suspected bacteremic infection in febrile granulocytopenic patients. Antimicrob Agents Chemother 1986;29:263-70.

16. The EORTC International Antimicrobial Therapy Cooperative Group. Ceftazidime combined with a short or long course of amikacin for empirical therapy of Gram-negative bacteremia in cancer patients with granulocytopenia. N Engl J Med 1987;317:1692-8.

17. Viscoli C, Van der Auwera P, Meunier F. Gram-positive infections in granulocytopenic patients: An important issue? J Antimicrob Chemother 1988;2 1:149-56.

18. Moellering $\mathrm{RC}$ Jr. In vitro antibacterial activity of aminoglycoside antibiotics. Rev Infect Dis 1983;5:S212-32.

19. Riben PD, Horsman GB, Rayner E, et al. Emergence of tobramycin-resistant Staph epidermidis possessing aminoglycoside modifying enzymes and bacteremic superinfection during empiric therapy of febrile neutropenic episodes. Clin Invest Med 1985;8:272-85.

20. Karp JE, Dick JD, Angelopulos C, et al. Empiric use of vancomycin during prolonged treatment-induced granulocytopenia. Randomized, double-blind, placebo-controlled clinical trial in patients with acute leukemia. Am J Med 1986;81:237-42.

21. Shenep JL, Hughes WT, Roberson PK, et al. Vancomycin, ticarcillin, and amikacin compared with ticarcillinclavulanate and amikacin in the empirical treatment of febrile, neutropenic children with cancer. N Engl J Med 1988:319:1053-8.

22. Pizzo PA. Hathorn JW, Hiemenz J, et al. A randomized trial comparing ceftazidime alone with combination antibiotic therapy in cancer patients with fever and neutropenia. N Engl J Med 1986:315:552-8.

23. Rubin M, Hathorn JW, Marshall D, Gress J, Steinberg SM, Pizzo PA. Gram-positive infections and the use of vancomycin in 550 episodes of fever and neutropenia. Ann Intern Med 1988;108:30-5.

24. European Organization for Research and Treatment of Cancer, International Antimicrobial Therapy Cooperative Group and the National Cancer Institute of Canada Clinical Trials Group. Vancomycin added to empirical combination antibiotic therapy for fever in granulocytopenic cancer patients. J Infect Dis 1991;163:951-8. 


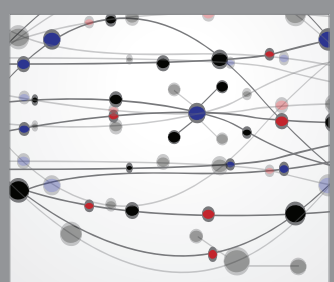

The Scientific World Journal
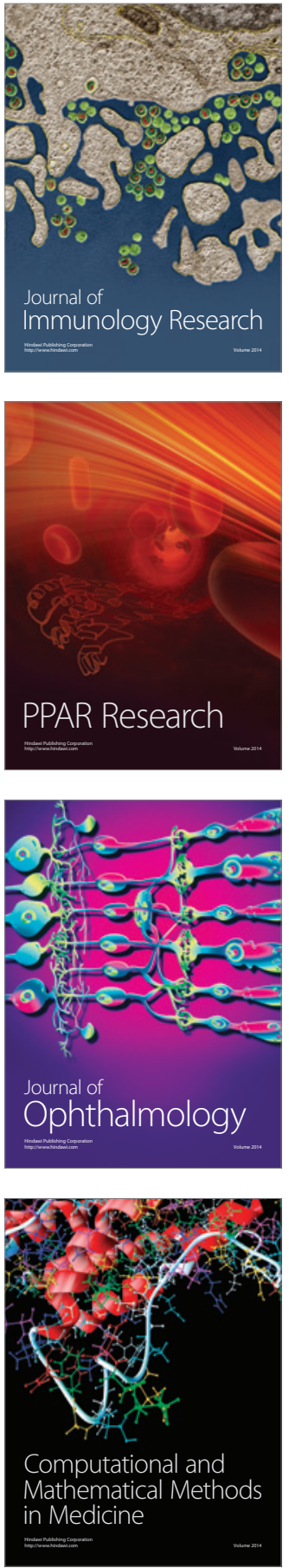

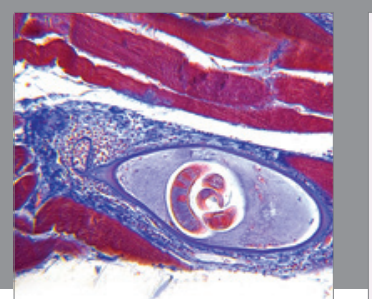

Gastroenterology Research and Practice

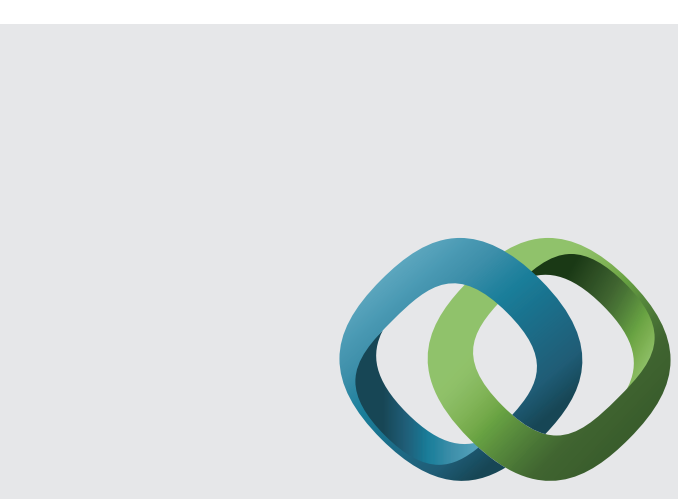

\section{Hindawi}

Submit your manuscripts at

http://www.hindawi.com
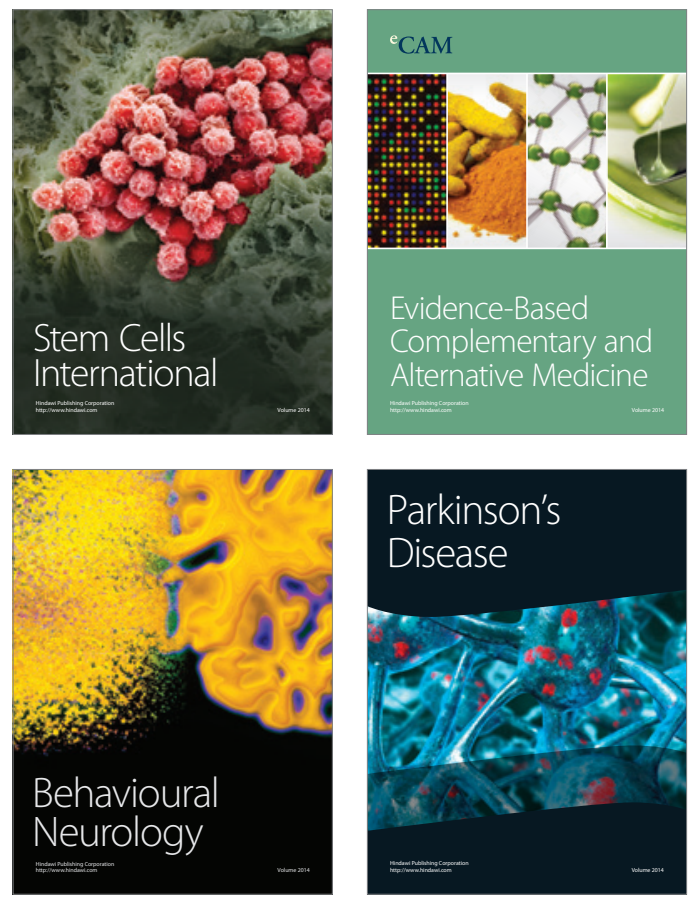
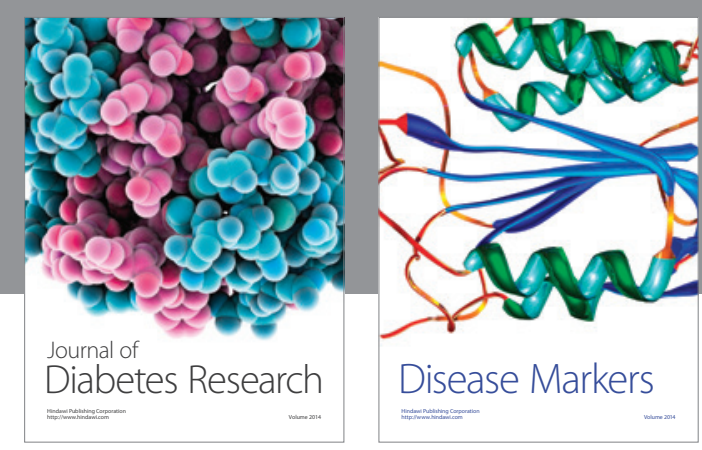

Disease Markers
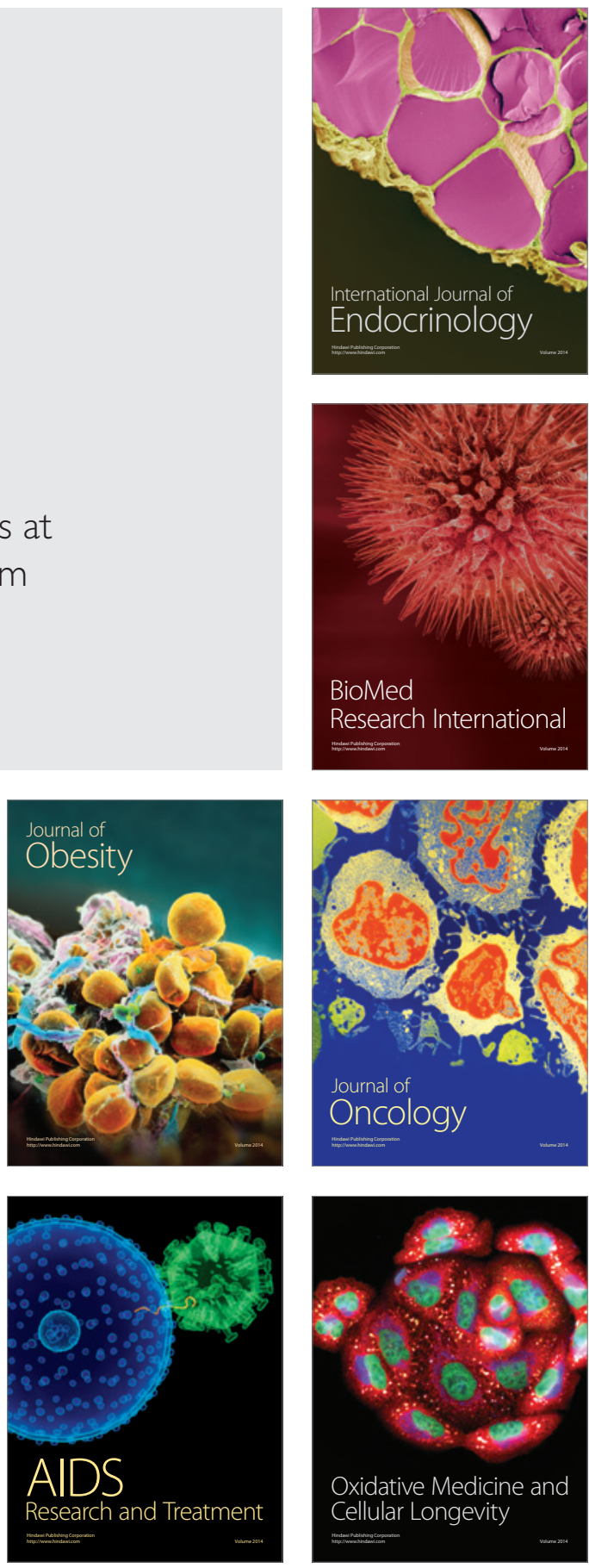